\title{
Collaborations Between Under-Resourced High School Students and STEM Professionals to Increase Participation in Science and Engineering Fairs
}

\author{
C. Todd
}

\section{ABSTRACT}

Industries in Science, Technology, Engineering, and Mathematics have enriched the economy of the United States. The US economy is dependent on educators to lead under-resourced high school students to STEM majors in college and careers through educational K-12 programs. Students who conduct high school research and participate in national and international science fairs receive substantial experiences to catapult them into STEM fields. High school students in the central region of Waterside School District have historically less participation in the regional science and engineering fairs than north and south regions due to lack of research skills acquired through collaboration and mentoring with STEM professionals to develop STEM projects. A program to connect the under-resourced students with STEM professionals to collaborate and mentor students about their research was implemented by the local school district. Scientific Research Saturday's program was positively received by non-focused high school students, however, the target group had limited attendance. Recommendations for program revisions include ementoring for students to accommodate transportation, hosting the workshops in more central locations for the focus group, and incorporating reflections by STEM professionals after workshops to improve effectiveness of sessions moving forward.

Keywords: Equity in Education, Mentorship, Science and Engineering Fair, STEM Professionals, STEM Research, Under-resourced Secondary Students

Published Online: January 1, 2021

ISSN: $2736-4534$

DOI : 10.24018/ejedu.2022.3.1.205

C. Todd

Dade County Public Schools, Miami, USA.

(e-mail: toddgib87@gmail.com)

\section{INTRODUCTION}

Industries in Science, Technology, Engineering, and Mathematics (STEM) have enriched the economy of the United States. The U.S. Department of Commerce, STEM Jobs, 2017 Update, indicated that the country's economic wellbeing depends on STEM industries. It reported that STEM workers drive our nation's innovation and competitiveness by generating new ideas and companies. People working in STEM fields are more likely to apply for and to develop patents. While STEM represents several jobs, it also represents many required skills needed in the workplace such as critical thinking, creative problemsolving, and technological processes (U.S. Department of Commerce, 2017). It is critical that STEM education is fostered in under-resourced youth to ensure that the pipeline into these fields continue and that equity in education exists. When students experience STEM throughout the K-12 education and from a young age, familiarity with STEM fields are stronger, which may direct them to choose these fields as their majors in college and their careers.

Reports by the U.S. Department of Commerce, (2017) showed that STEM jobs had increased to $6.6 \%$ of all jobs since 2015 and that growth of STEM jobs will increase more than $2.5 \%$ than non-STEM jobs between 2014 to 2024 . STEM workers will demand $29 \%$ higher salaries and have more degreed people than non-Stem workers. These data points indicate that under-resourced youth need continuous knowledge and skills in STEM to meet the growing demands of the workplace and to affect the nation's economy positively. In particular, mentoring by STEM professionals to support under-resourced high school students to do quality research and compete in national and international STEM competitions is key.

Policy makers and researchers address the need to maintain the flow of students into STEM related majors to pursue STEM careers through development of educational programs for K-12 students. However, national statistics indicate that today's students are not prepared today nor to meet future demands, (TIMMS, 2015; PISA, 2018). For instance, Trends in International Mathematics and Science has shown that United States 8th grade students have not made significant difference in knowing and reasoning in science and declined in mathematics in 2011- 2015. Additionally, PISA scores have shown that there was no significant difference in scientific and mathematical literacy in 2013- 2015. The implication is that the U.S.'s global leadership is in danger. In order to change the direction, the United States must put more effort on K-12 students to enter STEM fields (Sahin, 2013).

Secondary students within a large school district in the Southern United States which will be called Waterside 
School District showcase their STEM research ideas annually at the Waterside Regional Science and Engineering Fair (WRSEF). Each year participation has increased and is currently over 950 submissions, representing the winning projects from local science fairs at approximately 200 secondary schools. While most of the submissions demonstrate proficiency in the scientific process skills, only $25 \%$ meet the standards to advance to the next levels of competition, the State and International Science and Engineering Fairs. This is due to the development of projects which represent mere experiments and do not address real life problems. Components of winning projects are that they advance information in STEM, answer questions about problems in the world, demonstrate proficiency in experimental design and data analysis, and have appropriate and necessary real-life applications. Projects that are competitive to advance are usually done by students that have completed summer internships with STEM faculty at universities or by students that have professional or resourceful mentors in the fields of student interests. High school students who compete and win at local, national, and international science fairs usually work with parents, mentors, and professionals knowledgeable in STEM research and who direct them through the process of research.

The problem of focus for this paper is that students in the Central region of the Waterside District have traditionally submitted less science fair projects to WRSEF. The Central region represents more schools with students that are underresourced, within areas of low socio-economic status, and with high population of minority students than schools in the North and South regions. These schools tend to focus on reading and mathematics skills and interventions rather than academic enrichment in STEM. High school students from the Central region of Waterside District lack skills, developed through guidance and mentoring, necessary to conduct research and present research products competitively at local, state, and international science fairs because of their limited opportunities to collaborate with STEM professionals. Consequently, high school students in the Central region of Waterside District have historically less participation and success in regional, state, and international science fairs.

Under-resourced students are disadvantaged by not having mentors to assist them in developing research that will benefit them in competing in national and international science fairs, winning scholarships to universities and programs, and strengthening their confidence and passion for STEM fields. To affect this problem, a program to connect under-resourced high school students in the Central region of the school district with STEM professionals was developed. STEM professionals engaged students through TED Talks about their research and then collaborated with students to develop their individual research ideas into projects that would be submitted to the regional science and engineering fair. There has been countless studies examining the conditions to increase student involvement in STEM activities, however, limited information exists about mentoring under-resourced high school students to conduct research for science and engineering competitions through collaborations with STEM professionals that this paper will address.

\section{DEFINITIONS}

Under-resourced is defined by Oxford Learners Dictionary as not provided with as much money or as many staff, materials, etc. as are needed. Macmillan Dictionary defines under-resourced as without enough money or equipment to operate effectively. Under-resourced is described in context as schools or students that lack staff, materials, and money to engage in extra-curricular activities in STEM. STEM Professionals are individuals that have or are in pursuit of a doctorate or graduate degree in STEM or hold a STEM job.

\section{RESEARCH REVIEW}

The study by Estrada et al. (2016) suggested that academic pathways in STEM leak more for underresourced minorities than whites or Asian STEM students. As a result of under-resourced students having less representation and equitable opportunities in STEM, representation in the US STEM workforce is not diverse. Deliberate efforts are needed to repair the shoddy pipeline of minority students in STEM. "Change begins by recognizing the fields of influence in a situation and identifying the points at which there are "gatekeepers" that impede the flow of change in a system" (p.3). Estrada et al. (2016) assert that to cause change, the following steps should be used: evaluate, diagnose, plan action, take action, evaluate.

There is a direct relationship between students' STEM after school clubs and science fair participation and their college STEM major choice. The study by Sahin (2013) described a Texas charter school system that required all 4th through 12th graders to participate in annual science fairs. The requirements of students to participate in STEM after school clubs and to develop science fair projects included underrepresented groups such as African American, females, and economically disadvantaged students. The extracurricular STEM experiences resulted in the charter school system outperforming the national average in terms of post-secondary admissions and STEM majors' selections. Students who attended STEM after school clubs had a higher percentage of post-secondary matriculation in STEM majors than the national average implicating that engaging students with STEM-related clubs from earlier years of their education cultivates STEM interest in students to pursue STEM careers.

Mentoring students increases self-confidence and interest for student participation in science fairs. Sahini and Onder (2014) conducted a study to determine the impacts of the science exhibition on secondary school student researchers in charge in Turkey. Students participated in science fairs in which the experimental design, results and procedures of projects in biology, chemistry and physics were presented to the public. In the study, teachers were responsible to organize the science fair but only interacted with students, to help with experiments discussion if necessary. (Sahini \& Onder, 2014).

The impact of the science exhibition on secondary school 
student researchers was determined by responses to interviews. Interviews from students revealed major positive emotions that were categorized as communication, experience, awareness, and knowledge. Students reported that communication was positive, especially with friends and that they enjoyed communication next with people, and then with teachers and family. Other experiences that contributed to positive emotions/skills were due to having a good time, being curious, controlling the excitement, feeling himself/herself be important, being aware of the responsibilities and being aware of his/her own deficiencies/faults. Obtaining new information, applying the new information, and remembering the old information also generated positive emotions for students (Sahini \& Onder, 2014). Similarly, the Society for Science and the Public, governing bodies of International Science and Engineering Fair, recommend that students learn, grow, connect at STEM competitions to gain their greatest benefits from the experiences (Society for Science and the Public, 2019).

The interviews with students in the study by Sahini and Onder (2014) also revealed the major negative emotions that were related to deficiencies from teachers including lack of coordination, losing students' passions, obligations, and giving difficult topics to students. The audience impacted students negatively due to negative reactions of the guests, and unreactive reactions of the guests. Negative emotions were also related to environmental conditions and students' lack of interest to each other (Sahini \& Onder, 2014). Having conversations with science fair coordinators and teachers about stimuli to affect students' emotions can impact students' overall experiences at science fairs.

\section{STRATEGIES TO IMPROVE SRS PROGRAM}

Mentoring is an effective strategy to support underresourced high school students, however, access to mentors, particularly where geographic and time barriers are concerned, and reduced cost must be considered. The study by Ensher et al. (2003) identified electronic mentoring (ementoring) as a key strategy for supporting the retention, persistence, and graduation of underrepresented postsecondary students with disabilities in STEM majors. Effective mentoring experiences are influenced by multiple factors, including the purpose, the relationship between the mentor and the mentee, the consistency in the mentoring relationships and the mentoring objectives. While advantages associated with e-mentoring include access to mentors and reduced cost, challenges to e-mentoring are difficulty communicating nonverbally, slower development of relationships, wide-range of written communications skills and technology barriers. The findings of the study were that mentors greatly affected the personal and academic lives of mentees. Mentees recognized strongest gains during the mentoring, including the development of trusting and supportive relationships, self -determination, and self -advocacy.

Nelson et al. (2017) asserted that there is a valuable reciprocal relationship between STEM professionals and youth gained through mentoring. The study conducted focused on how undergraduate STEM mentors reflect upon their mentoring experiences in an outreach program engaging K-8 youth. Results showed that undergraduate student reflection about their mentoring experiences can inform the design of mentoring programs in order to ensure academic benefit for the undergraduate student as well as the students they are mentoring. "In this way, prompts for reflection after teaching will promote active monitoring, evaluating and modifying (of) one's thinking to help undergraduate mentors make sense of the experience, problem solve, and adapt to different teaching (and learning) environments" (pg.2). Additionally, promoting selfevaluation after mentoring can encourage the undergraduate student to consider both their own content knowledge and how to best support younger students in life science lessons (Nelson et al., 2017).

Tenenbaum et al. (2014) described a similar study to Nelson et al. (2017) involving a near-peer mentor, an undergraduate or post-baccalaureate student who mentors middle and high school students in a mathematics and science program. The mentors introduce inquiry-based STEM modules to the students, offer educational and career guidance, build supportive relationships with their mentees, and encourage students to pursue their goals. Evidence from the study showed that mentoring youth ignited personal growth and development of participants. Mentoring experiences benefited both mentors and mentees to grow and mature as professionals, teachers, and scientists. Participants increased maturation in professional expectations, the importance of learning to be adaptable, subject area knowledge, oral and written language skills that all contributed to career development. (Tenenbaum et al., 2014).

\section{SCIENTIFIC RESEARCH SATURDAYS PROGRAM}

High school students from the Central region of Waterside School District lack skills, developed through guidance and mentoring, necessary to conduct research and present research competitively at local, state, and international science fairs because of their limited opportunities to collaborate with STEM professionals. As a result of the problem with the under-resourced high school students, the Scientific Research Saturdays (SRS) program was developed and implemented for students in the Central region of the Waterside School district. The intent of the program was to connect under-resourced students to STEM professionals from local higher education institutions to collaborate about students' research ideas and to develop competitive research projects. The goal for students was to complete projects for submission to compete at local schools, District, State and International science and engineering fairs.

The process to develop the SRS program began with planning meetings between community enthusiasts interested in equity for students to do research and the members of the science department at the school district. Members of the committee planned outreach to high school students, marketing schedules, program logistics, STEM professional selection process and expectations, and program deliverables. Deliberate effort was taken to ensure students' safety therefore students met with STEM professionals exclusively at the events sponsored by the 
school District rather than with STEM professional at their work relations.

\section{A. Outreach and Marketing Schedule}

Outreach and marketing schedule: Outreach to high school students were made through invitations to teachers for professional development. Invitations were formally sent through a District weekly briefing to secondary schools sent directly to principals, assistant principals, and teachers and was followed up through monthly emails to science fair coordinators. Science fair coordinators were asked to inform secondary students interested in conducting research in STEM areas of the SRS program. The emails were attached with a flyer intended for students and teachers, registration links for students and teachers to attend, and directions for teachers to receive master plan points for participation in the workshops. Invitations to participate in SRS were later extended to high school students across all regions and then middle school students across all regions based on low numbers of registrants for the first SRS session.

\section{B. Logistic}

Three SRS workshops were held in two locations of the district, one in the north region of the county at a local community college and the other in the central region of the county at a major university. SRS workshops were held twice at the north location at and once at the central location. Sessions were held once monthly from 9AM to 12 PM every second Saturday for 3 consecutive months. The SRS workshops coincided with the schedule of student research being done at local schools to compete at the Regional Science and Engineering Fair.

\section{STEM Professional's Selection Process and Expectations}

STEM professionals were invited by the community liaison and District Science department to the program. The members were affiliated to various local and national universities and organizations. STEM professionals were mainly $\mathrm{PhDs}$ and graduate students and consisted of few professors and community leaders. STEM professionals were selected based on peer associations and invitations by professors to graduate students at host universities. STEM professionals' research represented science fair categories and they were open to present to students based on their own styles. Expectations of the mentors were to engage students with 3-minute TED talks of their research, offer research ideas based on their topics, and hold individual or small group collaborations with students to assist with the development of students' research project.

\section{Program Deliverables}

Specific deliverables were set for each workshop and escalated to students' finished research projects.

Session 1: Students will identify research topics, questions, and experimental designs.

Session 2: Students will refine experimental designs and data collection processes.

Session 3: Students will discuss data collected, results, ways to showcase data, and practice presentation skills.

\section{RESULTS AND FINDINGS OF SRS PROGRAM IMPLEMENTATION}

The outcome of the program was successful in supporting a few under-resourced students in the Central region; however, the number of students was expected to be much greater. The targeted high school students from the Central region represented only 10 percent of the students that participated in the SRS program overall. The majority participation was from non-targeted high school students (44\%) and middle school students (46\%).

The targeted high school students only attended the session which was in the Central region of the Waterside school district. This may be because the location was closer to their homes or that they were attracted to the major university. SRS attendance was highest at the session in the central location at a major university. One student travelled from the opposite end of the county to participate in the last session held in the north of the county. Parents of the students expressed gratitude, however, were dismayed by the long commute to the north location and requested more sessions in central and south areas.

The ratio of STEM professionals to students was adequate for all sessions. STEM professionals were more numerous and shared research representing more science fair categories in the central location at a major university. Six STEM professionals from the host university in the central location presented their work in chemistry. This may have been due to the convenience of being affiliated to the host university. Additional STEM professionals traveled from out of state to participate at the major university.

The content presented by STEM professionals was current and addressed community needs. Both students and teachers asked several questions after the presentations. Students connected with STEM professionals that their project ideas aligned with or that were most interesting to them during the workshops. During the second round of collaborations, students met with other STEM professionals to gain insight on how to further improve their experimental designs, data collection, and analysis processes. Both teachers and students expressed satisfaction for the help that they had received during the sessions.

Student responses to the STEM professionals Ted Talks were also consistent. When STEM professionals discussed their research starting with the needs and problems that they tried to address and held interactive presentations involving students, students seemed more focused and asked more questions. When presentations surpassed 3 minutes, did not present the need or applications that were understood by the audience, were not interactive, students lost focus, which was evidenced by them using phones, looking around, and paying attention to the timekeeper. Inconsistencies with the format of presentations by STEM professionals affected the expected program outcome and responses by students. STEM professionals were initially directed to give 3-minute TED talks, however, could surpass the time sometimes by 2 minutes. Presentations mostly encompassed topics in biology and chemistry instead of the intended variety of categories represented at the local, national, and 
international science fairs. The level of interactivity with the audience varied greatly with STEM professionals. The program did not include reflective feedback by STEM professionals that would have been necessary to address subsequent SRS sessions or to develop themselves professionally.
It would help to inform the group's knowledge of gaps in the teaching and learning in K-12 STEM research to address the gaps for undergraduate learners. Feedback sessions would help STEM professionals and organizers to adhere to implementation guidelines more consistently. Revisions should include strategies to improve preparedness by STEM professionals. For example, program planning meetings could be face to face or virtually, however, would include expectations and guidelines.

TABLE I: NUMBERS OF PARTICIPANTS AT THE SCIENTIFIC RESEARCH SATURDAY PROGRAM

\begin{tabular}{ccccccc}
\hline \hline SRS Session & \# of Students & $\begin{array}{c}\text { \# of Students from } \\
\text { Central Region }\end{array}$ & $\begin{array}{c}\text { \# of HS } \\
\text { Students }\end{array}$ & $\begin{array}{c}\text { \# of MS } \\
\text { Students }\end{array}$ & $\begin{array}{c}\text { \# of STEM } \\
\text { Professionals }\end{array}$ \\
\hline 1- North & 15 & 0 & 10 & 5 & 6 & 3 \\
2- Central & 73 & 9 & 37 & 36 & 13 \\
3- North & 1 & 0 & 1 & 0 & 6 \\
\hline Total & 89 & 9 & 48 & 41 & 25 \\
\hline \hline
\end{tabular}

\section{RECOMMENDATIONS - PLAN FOR REVISION OF SRS}

The SRS intervention program used to address the problem of low submissions of science and engineering fair projects by under resourced high school students will be reevaluated as suggested Estrada et al. (2016) to cause change. The SRS program was successful in meeting the needs of students to develop science fair projects and to teach the process of research. However, the targeted group, high school students in the Central region of the District, had the lowest participation in comparison to students in the north and south regions. In order to increase participation and reduce the need to find transportation to the SRS sessions, e-mentoring will be available for students, as per suggestions by parents and students. Students will have the opportunity to Skype into the sessions to view presentations by STEM professionals and participate in workshops. Another change with the SRS program will be to hold all the sessions at the central location, rather than in the north as was done in the original format, for convenience to travel to the workshops. Since the focus for increased exposure and mentoring is for under-resourced students in the central region, students should access the resources directly.

The SRS program will be revised to include feedback segments after each session for organizers and STEM professionals. This would provide STEM professionals opportunities to internalize their experiences with participants to refine the later sessions efficiently and to develop themselves as researchers and community members.

\section{REFERENCES}

Estrada, M., et al. (2016). Improving underrepresented minority student persistence in stem. CBE life sciences education, 15(3), [es5]. https://doi.org/10.1187/cbe.16-01-0038

Gregg, N., Wolfe, G. Jones, S., Todd, R., Moon, N., Langston, C. (2017). STEM E-Mentoring and Community College Students with Disabilities. Career Development and Transition for Exceptional Individuals, SAGE, 40 (4), 47-63.

MacMillan

Dictionary, https://www.macmillandictionary.com/dictionary/british/underresourc ed.

Nelson, K., Sabel, J., Forbes, C., et al. (2017). How do undergraduate STEM mentors reflect upon their mentoring experiences in an outreach program engaging K-8 youth? International Journal of STEM Education, 4(3). doi:10.1186/s40594-017-0057-4.

\section{CONCLUSION}

Deliberate efforts to connect under-resourced students to STEM professionals will increase students' skills to do research. It is evident by national statistics that the plan suggested by Estrada et al. (2016) to evaluate, diagnose, plan action, take action, and re-evaluate should be employed to cause change to ensure that minorities do not slip through holes of the STEM pipeline to enjoy and benefit from STEM degrees and careers. Gatekeepers of the plan include STEM educators in K-12 and higher education should be knowledgeable of how to support under-resourced students into STEM worlds. Collaborations with STEM professionals will provide students guidance and mentoring needed to develop competitive science fair projects and confidence to pursue unthinkable objectives related to STEM.

The onus to establish equity in education continues to be on educators. Educators need to work with professionals in STEM to build their own knowledge to help students more directly to develop skills to conduct research. Research skills are essential to success in college and support readiness for careers in STEM. Working directly with under-resourced students will increase their chance to engage in STEM opportunities and to be included as contributors of world problem solvers and forces that positively affect the nation's economy.

Oxford

Learner's

Dictionary, https://www.oxfordlearnersdictionaries.com/definition/english/underresourced

Programme for International Student Assessment PISA. (2018). International student assessment (PISA) - Science performance (PISA)

Sahin, A. (2013). STEM Clubs and Science Fair Competitions: Effects on Post-Secondary Matriculation, Journal of STEM Education, 14(1), 511.

Şahin, E., Önder Çelikkanli, N., Onsekiz, C. (2014). The Impacts of a Secondary School Science Exhibition on The Students in Charge, NFE-EJMSE, 8(2).

Trends in International Mathematics and Science Study (TIMSS). (2015). Trends in International Mathematics and Science Study (TIMSS)Welcome to TIMSS and TIMSS Advanced Results from 2015

Tenenbaum, L.S., Anderson, M.K., Jett, M. et al. (2014). An innovative near-peer mentoring model for undergraduate and secondary students: STEM focus. Innovative Higher Education, 39, 375-385. https://doi.org/10.1007/s10755-014-9286-3 
European Journal of Education and Pedagogy

www.ej-edu.org

U.S. Department of Commerce. (2017). STEM Jobs.

https://www.commerce.gov/news/reports/2017/03/stem-jobs-2017- 